\title{
Impacto dos Biossimilares no Tratamento da Psoríase
}

\author{
Impact of Biosimilars in Psoriasis Treatment
}

Tiago TORRES ${ }^{1,2}$, Paulo FILIPE ${ }^{3,4,5}$, Manuela SELORES ${ }^{1,2}$

Acta Med Port 2013 Nov-Dec;26(6):646-648

Palavras-chave: Agentes Biológicos; Psoríase/tratamento; Medicamentos Biossimilares.

Keywords: Biological Agents; Biosimilar Pharmaceuticals; Psoriasis/drug therapy; Portugal.

A psoríase crónica em placas é uma doença cutânea inflamatória, imunomediada com um importante impacto na qualidade de vida dos doentes ${ }^{1}$ e estima-se que afecte 250 mil Portugueses. Avanços no conhecimento da imunopatogenia da psoríase levaram ao desenvolvimento de medicamentos biotecnológicos, que interferem selectivamente em mecanismos de acção da doença. Tal como noutras áreas da medicina, os agentes biológicos revolucionaram o tratamento da psoríase, demonstrando ser seguros e eficazes, constituindo uma alternativa aos tratamentos sistémicos convencionais e uma importante instrumento ao dispor do dermatologista no tratamento da psoríase moderada a grave. ${ }^{2}$ Calcula-se que existam em Portugal cerca de 6000 doentes com indicação para terapêutica biológica, estando disponíveis, actualmente, quatro agentes biológicos para o tratamento da psoríase: Adalimumab (Humira ${ }^{\circledR}$, Abbvie), Etanercept (Enbrel ${ }^{\circledR}$, Pfizer), Infliximab (Remicade ${ }^{\circledR}$, Janssen Biotech) e Ustekinumab (Stelara ${ }^{\circledR}$, Janssen Biotech).

Os medicamentos biotecnológicos, também denominados de agentes biológicos, são proteínas produzidas por organismos vivos utilizando tecnologia de ADN recombinante. ${ }^{3}$ Diferem entre si no que respeita à dimensão, complexidade da estrutura e potencial imunogénico, podendo ser produtos idênticos a moléculas produzidas pelo organismo humano, como a insulina, a hormona de crescimento e a eritropoietina, anticorpos monoclonais que se ligam a proteínas solúveis ou de superfície bloqueando células ou vias celulares ou proteínas que mimetizam receptores celulares.

Ao contrário dos medicamentos de síntese química, os agentes biológicos têm estruturas complexas e elevado peso molecular, pelo que pequenas diferença no seu método de produção podem causar diferença na molécula final. ${ }^{4}$ De facto, mesmo entre lotes do mesmo produto poderá existir um certo grau de variabilidade.

A perda de patente dos primeiros agentes biológicos levou ao desenvolvimento de moléculas com estrutura similar aos originais, denominados de biossimilares, com o objectivo de diminuir os custos associados às terapêtica biológicas e aumentar a acessibilidade a estes medicamentos, particularmente importante no tratamento de doenças crónicas. De acordo com a Organização Mundial de Saúde, os biossimilares são medicamentos biológicos que são similares (definido como ausência de diferenças relevantes no parâmetro de interesse) em termos de qualidade, segurança e eficácia a medicamentos biológicos de referência já aprovados, ${ }^{5}$ nos quais a segurança e eficácia no uso clínico foi devidamente demonstrado através de estudos pré-clínicos e clínicos. Os biossimilares devem garantir similaridade,em relação ao produto de referência, de parâmetros como a sequência de aminoácidos, conformação, modificação pós-translacional, imunogenicidade, função e afinidade aos seus ligandos.

No entanto, os medicamentos biossimilares não são genéricos, pois os genéricos têm estruturas químicas e processos de produção mais simples sendo considerados idênticos aos respectivos medicamentos de referência, qualitativa e quantitativamente e em termos de biodisponibilidade e bioequivalência. ${ }^{6}$

No caso dos agentes biológicos, após a perda de patente, o processo de fabrico, além de mais complexo, não tem que ser divulgado ${ }^{7}$ pelo que a probabilidade de diferenças no processo de fabrico dos biossimilares relativamente ao dos produtos de referência originais é elevada. De facto, a produção de uma cópia igual de um medicamente biológico é virtualmente impossível, devido à sua estrutura complexa e heterogénea. Assim, é provável que estas diferenças, nomeadamente em termos de processo de fabrico possam conduzir a diferenças entre as terapêuticas biológicas e os biosimilares. ${ }^{7}$

A capacidade de provocar uma resposta imune com produção de anticorpo anti-fármaco, conhecida por imunogenicidade, é um problema transversal a todos os agentes biológicos, incluindo os biossimilares, com implicações clínicas importante especialmente em termos de segurança. ${ }^{8}$ Desta forma, devido às possíveis diferenças de estrutura

1. Serviço de Dermatologia. Centro Hospitalar do Porto. Porto. Portugal.

2. Instituto de Ciências Biomédicas Abel Salazar. Universidade do Porto. Porto. Portugal.

3. Consulta de Psoríase. Serviço de Dermatologia. Centro Hospitalar Lisboa Norte. Lisboa. Portugal.

4. Faculdade de Medicina. Universidade de Lisboa. Lisboa. Portugal.

5. Unidade de Investigação em Dermatologia. Instituto de Medicina Molecular. Universidade de Lisboa. Lisboa. Portugal.

Recebido: 18 de Novembro de 2013 - Aceite: 05 de Dezembro de 2013 | Copyright $\odot$ Ordem dos Médicos 2013 
entre os agentes biológicos originais e os biossimilares, é possível que a capacidade imunogénica possa ser diferente entre eles.

Em Julho de 2012 a Korea Food and Drug Administration aprovou o CT-P13 (Remsima ${ }^{\circledR}$, Celltrion), o primeiro anticorpo monoclonal considerado um biossimiliar do Infliximab (Remicade ${ }^{\circledR}$, Janssen Biotech). Em 2013, a EMA aprovou a sua utilização na Europa, baseada num único ensaio de equivalência, efectuado em doentes com artrite reumatóide, suplementado num estudo de farmacocinética na espondilite anquilosante, tendo sido ainda aprovado nas restantes indicações do Infliximab (doença de Crohn, colite ulcerosa, artrite psoriática e psoríase), apesar de o CT-P13 não ter sido estudado nestas populações. ${ }^{9}$

Atendendo à complexidade dos biossimilares e a todas as implicações associadas ao seu aparecimento, a emissão de recomendações de utilização pelas autoridades de saúde, colégios de especialidade e sociedades científicas tornam-se imprescindíveis.

Com este artigo, os autores pretendem comentar e assinalar os principais pontos de discussão e de maior complexidade na abordagem deste tema. Assim, os autores consideram que os tratamentos eficazes devem ser disponibilizados aos doentes ao menor custo possível e que os biossimilares poderão associar-se a uma diminuição dos custos, permitindo uma maior acessibilidade dos doentes a medicação biotecnológica. Contudo, a segurança do doente deve ser a prioridade, pelo que decisões sobre a utilização de biossimilares e interpermutabilidade devem ser conduzidas de acordo com a evidência científica tendo em consideração vários princípios orientadores:

1. Diferenças subtis na produção dos agentes biológicos podem afectar as suas propriedades funcionais, tanto em eficácia como em segurança. Assim, para que um fármaco em desenvolvimento seja considerado "similar" ao original deve, de acordo com a presente regulamentação Europeia, passar por todas as fases de desenvolvimento pré-clínico e clínico.

2. A aprovação obtida para determinada indicação não deve permitir a extrapolação para as outras indicações dos medicamentos inovadores sem uma confirmação mínima de eficácia e segurança na indicação em causa. A possível variabilidade que existe entre o produto de referência e o biossimilar, os regimes posológicos diferentes e as diferenças intrínsecas entre as patologias, em termos de mecanismos fisiopatológicos, comorbilidades associadas e medicação concomitante, não garante a mesma eficácia e segurança nas diferentes indicações. Deste modo, os resultados obtidos em estudos na artrite reumatóide, espondilite anquilosante, doença inflamatória intestinal ou outras não devem ser extrapolados para a psoríase e artrite psoriática.

3. De forma semelhante aos medicamentos de referência, para a obtenção de aprovação numa determinada indicação, os biossimilares devem ser avaliados em ensaios clínicos especificamente concebido para essa patologia, uma vez que a bioequivalência pode não corresponder a equivalência terapêutica. Assim, a extrapolação deve ser vista com precaução caso não esteja garantida a eficácia, pela ausência de ensaios clínicos, nem completamente salvaguardado o princípio da precaução em termos de segurança.

4. A imunogenicidade é um risco associado aos medicamentos biológicos, com potencial impacto na eficácia e na segurança dos tratamentos e pode ser diferente entre os agentes biológicos originais e os biossimilares. Assim, testes para detecção de anticorpos anti-fármaco devem fazer parte dos ensaios clínicos com biossimilares.

5. A EMA não se pronunciou relativamente à interpermutabilidade e substituição automática (troca do medicamento original pelo medicamento biossimilar ou vice-versa de acordo com a opinião/decisão médica ou sem autorização médica respectivamente) tendo deixado esta decisão ao cuidado dos estados membros. ${ }^{10}$ A substituição automática de um medicamento original por um biossimilar ou vice-versa deve ser considerada uma alteração ao tratamento, não devendo ser uma prática sem o conhecimento e o consentimento do médico prescritor ou informação do doente, para além de dificultar os procedimentos de farmacovigilância.

6. O biossimilar deve ter uma denominação própria para eliminar qualquer confusão, de modo a que a terapêutica seja controlada com precisão pelos diferentes profissionais de saúde envolvidos e que, em caso de efeitos adversos, seja possível identificar correctamente a terapêutica responsável por tal evento.

7. Após a aprovação do biossimilar, a farmacovigilância e os registos no período pós-comercialização, com a recolha de informação dos acontecimentos adversos, são essenciais na confirmação da segurança e na detecção de efeitos adversos menos comuns mas potencialmente importantes.

Em conclusão, os autores estão a favor do desenvolvimento de biossimilares, assim como da sua aprovação pelas agências reguladoras desde que sejam submetidos aos mais elevados níveis de qualidade em termos de produção e desenvolvimento e à avaliação de eficácia e segurança em programas de desenvolvimento completos, seguidos de um programa de farmacovigilância. A sua aprovação no tratamento de doentes com psoríase e artrite psoriática, deve depender da avaliação nesta população particular de doentes de modo a garantir padrões adequados de eficácia e segurança. As decisões clínicas devem ser efectuadas numa base individual, tendo sempre em consideração as circunstâncias do doente e da doença e tendo sempre como principal prioridade a segurança dos doentes.

Por fim, reitera-se a necessidade de as autoridades de saúde, os colégios de especialidade e as sociedades científicas emitirem pareceres e recomendações sobre a utilização de biossimilares em Portugal devido à elevada complexidade deste assunto, às potenciais implicações nos doentes, médicos e no sistema de saúde e à existência de lacunas regulamentares. 


\section{CONFLITO DE INTERESSES}

Tiago Torres foi palestrante e fez parte de Advisory Board da Abbvie, Janssen-Cilag, Leo-Pharma, MSD, Pfizer. Recebeu apoio para investigação: Abbvie, MSD e Pfizer. Participou em estudos observacionais e ensaios clínicos patrocinados pela Abbvie, Amgen, Janssen-Cilag, Merck-Serono e Novartis.

Paulo Filipe foi palestrante e fez parte de Advisory Board da Abbvie, Leo-Pharma, Janssen-Cilag, MSD, Pfizer. Recebeu apoio para investigação: Abbvie, Leo-Pharma, MSD e Pfizer. Participou em estudos observacionais e ensaios

\section{REFERÊNCIAS}

1. Gudjonsson JE, Elder JT. Psoriasis: epidemiology. Clin Dermatol. 2007; $25: 535-46$.

2. Torres T, Velho GC, Sanches M, Selores M. Psoríase na era dos biológicos. Acta Med Port. 2010;23:493-8.

3. European Medicines Agency. Questions and answers on biosimila medicines (similar biological medicinal products). London: EMA; 2012.

4. European Medicines Agency. Guideline on similar biological medicinal products. London: EMA; 2005.

5. WHO Expert Committee on Biological Standardization. Guidelines on Evaluation of Similar Biotherapeutic Products (SBPs). Geneve: WHO; 2010.

6. Abraham I, Sun D, Bagalagel A, Altyar A, Mohammed A, Tharmarajah $S$, et al. Biosimilars in 3D: definition, development and differentiation. clínicos patrocinados pela Abbvie, Amgen, Janssen-Cilag, Merck-Serono e Novartis.

Manuela Selores foi palestrante e fez parte de Advisory Board da Astellas, Galderma, Janssen-Cilag, Merck-Serono, Novartis, Pfizer. Participou em estudos observacionais e ensaios clínicos patrocinados pela Astellas, GlaxoSmith-Kline, Janssen-Cilag, Merck-Serono, Novartis e Pfizer.

\section{FONTES DE FINANCIAMENTO}

Os autores declaram a inexistência de fontes de financiamento externas na realização do presente trabalho.

\section{Bioengineered. 2013;4:203-6}

7. European Medicines Agency. Guideline on similar biological medicinal products containing biotechnology-derived proteins as active substances: quality issues. 201218 January 2013.

8. Schellekens $\mathrm{H}$. Immunologic mechanisms of EPO-associated pure red cell aplasia. Best Pract Res Clin Haematol. 2005;18:473-80.

9. European Medicines Agency. European Medicines Agency recommends approval of first two monoclonal-antibody biosimilars. London: EMA; 2013.

10. Guideline on similar biological medicinal products containing monoclonal antibodies - non-clinical and clinical issues. EMA/CHMP/ BMWP/403543/2010. London: EMA; 2012. 


\section{Impacto dos Biossimilares no Tratamento da Psoríase \\ Acta Med Port 2013:26:646-648}

Publicado pela Acta Médica Portuguesa, a Revista Científica da Ordem dos Médicos

Av. Almirante Gago Coutinho, 151

1749-084 Lisboa, Portugal.

Tel: +351218428 215

E-mail: submissao@actamedicaportuguesa.com

www.actamedicaportuguesa.com

ISSN:0870-399X | e-ISSN: 1646-0758

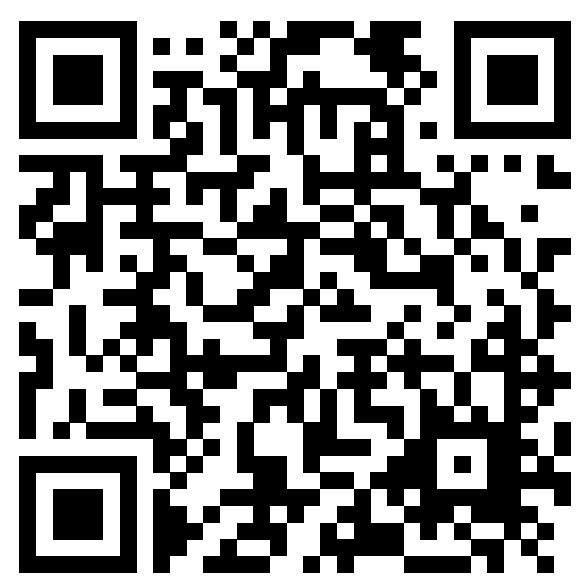

